Article

\title{
Growing Media Skills and Know-How In Situ: Technology-Enhanced Practices and Collaborative Support in Mobile News-Reporting
}

\author{
Efstathios Sidiropoulos *, Nikolaos Vryzas, Lazaros Vrysis ${ }^{\mathbb{D}}$, Evangelia Avraam and \\ Charalampos Dimoulas $(D)$ \\ Multidisciplinary Media \& Mediated Communication Research Group (M3C), Aristotle University, \\ 54636 Thessaloniki, Greece \\ * Correspondence: stathsid@jour.auth.gr
}

Received: 30 May 2019; Accepted: 28 June 2019; Published: 4 July 2019

\begin{abstract}
Over the past decade, mobile news production has had a growing prevalence and has been established as a new type by modern journalism industry. Journalists understand content capturing and sharing as parts of their role in newsrooms. Mobile journalism (mojo) is an evolving form of reporting in which where people use only a smartphone to create and file stories, and it has been gaining ground during the last decade. This paper aims to examine the difficulties, issues, and challenges in real-world mojo scenarios, analyzing the efficacy of prototype machine-assisted reporting services (MoJo-MATE). A usability evaluation is conducted in quantitative and qualitative terms, paying attention to the media literacy support provided through implemented tools and the proposed collaborations. Students of the School of Journalism and Mass Communications, along with postgraduate-level researchers and professional journalists, form the sample for this investigation, which has a two-folded target: To guide the rapid prototyping process for system development and to validate specific hypotheses by answering the corresponding research questions. The results indicate the impact of mobile/on-demand support and training on journalistic practices and the attitudes of future journalists towards specialized technology in the era of constantly evolving digital journalism.
\end{abstract}

Keywords: mobile journalism; media training; collaborative support; media literacy

\section{Introduction}

Undoubtedly, during the last decade we have witnessed a rapid and intense advancement of the information and communication technologies (ICTs), which has had a significant impact on the continuous transformation of the digital media landscape [1-5]. Newfangled digital journalism genres appear and continually evolve, extending the news-reporting and informing capabilities of all users, citizen, and professional journalists, while also requiring different skill sets and know-how on the use of digital media. The need for constant and on-demand support in these technologies and generally for the cultivation of digital literacy is among the contemporary priorities of the society. Furthermore, the proliferation of mobile devices (smartphones and tablets) and their communicative capabilities have intensified their role in technology-enhanced learning and everyday informatory services [1,6-13]. In this direction, mobile journalism (mojo) forms a representative example, in which both new tools (i.e., mojo apps for journalists and targeted audience) and learning resources have to be produced, shaped, and adapted to the users' needs and preferences [14-16].

Media literacy is considered crucial, especially among students and professionals of journalism, media, and communication. It is not surprising that the rise of information and communications technologies (ICTs) has had a major effect on the curricula of universities. The efficient integration 
of new media education and technologies is still a topic under investigation. While the use of available systems and platforms is very widespread, it does not always optimally address the new pedagogical needs. The most common academic approach in schools of journalism and media worldwide is to include discrete courses of theoretical background and practical laboratory training in the curriculum. Moreover, dedicated environments for technology enhanced learning (TEL) make use of new technological advances in order to support students individually [17].

Concerning the professional training of students and journalists, media literacy becomes a high priority, since many of them will have to cope with a new professional environment and emerging types of journalism, like multimedia [18] and data journalism [19]. Modern professionals are required to have much more advanced technical skills and a deeper understanding of digital products, as well as multimedia and web applications for cloud-based collaboration and publishing, in order to successfully respond to the needs of the industry [20-22]. Thus, besides revolutionizing traditional teaching approaches, the curricula are being reshaped drastically in order to cover several topics of ICTs that become crucial in the changing technological ecosystem. Students who receive training in specialized audio and radio production software and techniques within the university curriculum evaluate the procedure highly in terms of usefulness and satisfaction [23]. Professional journalists are also offered retraining opportunities through life-long education programs [24].

With the rise of mobile devices and ubiquitous computing, connectivity and high-performance functionality are offered anywhere and anytime. This has led to the appearance of a newly established learning methodology, mobile learning (m-learning) [25]. According to studies, the vast majority of university students own at least one mobile device [26], and more than half own several [25]. Case studies and related research have investigated the novel opportunities for the use of Web 2.0 or Participatory Web [27] and mobile learning [28]. Ashton analyzed them in the more specific scenario of journalistic training [29].

Mobile journalism or mojo refers to the explicit use of mobile phones for the creation of news reporting content. It can include the contributions of professionals, as well as user generated content (UGC) provided by amateur users. The only prerequisite are the use of commonly available mobile devices and their functionality. Mojo has been considered an opportunity along with the rapid spread of mobile devices and the rise of UGC and citizen participation during the last decade [30,31]. This new mobile technology potential caused both skepticism and excitement, but it was immediately embraced by the first mobile journalists (mojos) or solo journalists (sojos) [31]. However, the capabilities of that generation of smartphones still caused major quality drawbacks and often a disappointment to the professionals who used them for content creation [30].

It soon became clear that mojo could be useful for professionals as well, especially in cases of live reporting and broadcasting, where its flexibility and portability make it much more appealing than traditional newsroom mobile workstations and bigger crews [32]. While it seems adequate as part of common journalistic workflows, there is an urgent need for the adaptation of newsrooms infrastructures in order to gather, edit, and publish mojo content efficiently [33]. Mobile content creation and publishing is also associated with the respective rise of the popularity of mobile devices in the consumption of news stories [34,35]. Along with the spread of social media, mobile devices have become a powerful means for broadcasting by professional and amateur users [35]. This forces traditional media to evolve in the direction of becoming responsive to the various media and channels of interest in order to address a diverse audience. Moreover, the evolution of mobile journalism in the past years has led to the emergence of new distinct fields of journalism. "Selfie" photographs or "selfies," i.e., self-portrait photographs, have not just shaped the capabilities of modern smartphones by making the installation of a front camera an industry standard, they have reshaped modern journalism. Selfie journalism is the branch that deals with "selfies" as a journalistic tool $[36,37]$.

Livingstone pointed out that media literacy consists in the ability to access, analyze, evaluate, and create content in the new media [38]. Even more so today, these skills are essential in order to keep pace with modern technological possibilities and be media-active. Mojo includes practices and 
procedures that are held by both professional journalists and citizens. Having this common practice as a reference can help in the development of media-active citizens and more digitally literate societies. This may allow a wider audience to surpass the stage of exclusively consuming stories and also play an important role in content and story generation [39]. Burum in [40] presented a project-based approach of mojo training which proved to be very efficient for students of various education levels, schools, universities, and the media to acquire several skills related to media literacy. Such skills include the use of creating and editing audiovisual content with mobile cameras, microphones, and dedicated software; research through social media; creating interviews; writing; publishing across various web platforms; schedule/budget management; and multimedia storytelling. The program was considered especially useful for distance learning. This author supported the idea that mojo literacies and skills may form the basis of a common digital language (CDL) which can serve as a bridge between community, education, and media communication.

Mojo training is considered appropriate to address the three main elements of multimedia digital literacy as stated by Meyrowitz [41]: Content literacy, media language, and media literacy. In the case of the curriculum programs of journalism schools, the author of [40] proposed a 12 week mojo curriculum where the students would have the opportunity to learn and prepare for the complete workflow cycle of news creation and publishing. In the Hindustan Times, mojo has been integrated into the workflows as a discrete department. In order to train the journalists in the new digital mobile ecosystem, regular training sessions held by an expert were carried out and evaluated [42]. In these sessions, journalists are trained on new tools and processes, modern story-telling, new technologies, and social media. The question that arises is whether training journalists in a multi-skilling environment, where they have to be able to perform efficiently in multiple media, leads to en-skilling or de-skilling. This study finds that journalists are positive in gaining knowledge of all different branches of the industry. However, they point out that the training sessions, as well as the new responsibilities, add too much pressure to their time schedules [42]. In research done by Blankenship [43], many reporters favored having control over the totality of the published content but realized that having to cope with all these responsibilities may distract them from journalistic tasks. In the work of Perreault and Stanfield [44], it was stated that mojo skills are considered a requirement in labor market among new journalists, while experienced journalists are also often expected to retrain in order to acquire them.

MoJo-MATE is a newly introduced platform aimed at supporting journalists, reporters, and newsrooms in incorporating mojo [14-16]. Following the main/typical implementation phases (analysis, design, development, and evaluation) of software and multimedia production [45-51] that were also deployed in the case of MoJo-MATE prototyping [14-16], the current work pursues media literacy support by propelling best-practices adoption and offering (in-situ) digital support services, through responsive machine assistance and on-demand guidance/collaboration with other users. In this context, the present paper deals with highly-interdisciplinary ongoing media paradigms (confidently handled mainly by technology experts), focusing on the aspects of technology-enhanced (on-demand) learning, with a two-folded target: To present the analysis and evaluation of the MoJo-MATE rapid prototyping process and to validate specific hypotheses related to its educatory character and impact by answering the corresponding research questions.

The paper explores the impact of mobile learning on journalistic practices and the attitudes of future journalists towards the specialized technology used in education for context courses on a mass media curriculum.

More specifically, the hypotheses besides the conducted research were that a strong percentage of (traditional) journalists/reporters:

RH1: Are familiar with the idea of using their smartphones for content creation, editing, and sharing, and they would be willing to make use of a framework that supports them in such tasks.

RH2: Do not have the skillsets and know-how to fully exploit contemporary digital technologies in their every-day (media) work, nor do they have in-depth knowledge of the content production and management capabilities of smartphones and generally mobile devices (i.e., proper capturing, 
time-, location-, and context-aware tagging) to deploy them in favor of their news-reporting and publishing tasks,

RH3: Are willing to develop their skills without supplementary training, following an on-the-work learning procedure.

RH4: Can provide valuable feedback during the implementation of a dedicated mojo system, which, apart from the newly offered services, would also provide digital literacy support, both for the involved operations and for broader media processes.

Based on the above hypotheses, the research questions that were investigated are as follows:

RQ1: What are the various problems, issues, and challenges that mobile journalism is facing nowadays?

RQ2: What are the technological and functional capabilities of mobile devices/applications and their impact on the corresponding reporting needs? Are journalists (and generally targeted users) aware of those features and the associated technological capacities?

RQ3: Are the targeted users (students and citizen-/professional-journalists) interested in such applications and willing to participate in their development, thus shaping their main functional attributes? Are they interested in developing their media skills while making use of technological capabilities?

RQ4: What is the impact of the provided services as technology-enhanced learning resources for supporting both newly launched utilities and broader media processes or practices?

\section{Materials and Methods}

\subsection{Machine-Assisted Reporting in the Era of Mobile Journalism: The MoJo-MATE Platform}

A collaborative model for the support of journalists and reporters through the integration of intelligent mobile applications, cloud collaboration, and server support has been described in previous work [14]. For designing, prototyping, and evaluating the model, an interdisciplinary approach was adopted implementing a LUCID (logical user-centered interactive design) model methodology, which introduces iterative stages [14,52]. The aim of the project is to fulfill the needs of professionals and citizens who collaborate in news production and to address all the workflows of an interconnected newsroom, appropriate for the integration of mojo and intelligent systems. Besides the functionality that was proposed by the research group, the LUCID methodology also implies a focus on the requirements from the user's point of view, ensuring effectiveness, efficiency, quality of service, error tolerance, simple recovery, and ease of learning [47,52,53].

Following the aforementioned methodology, the mobile journalism machine assisted reporting (MoJo-MATE) platform was introduced [16]. MoJo-MATE is a platform that aims at offering functionality that covers the needs of all the contributors of a mojo newsroom, namely on-site reporters, citizen journalists, editors, multimedia experts, and tech staff, as well as the public. Moreover, it offers cloud connectivity that allows for file sharing and online collaboration between the members of the aforementioned group. The core architecture of the MoJo-MATE platform consists of two sides: The server and the terminal.

The terminal side is an iOS mobile application that covers the functionality of content creation, editing, and sharing. One of the main limitations of mojo lies in the quality of the created content. This is partly due to the low budget equipment of mobile devices in comparison to the professional equipment that is commonly used in news creation, but, mostly, it is due to the improper use of the available cameras and microphones. In most realistic mojo scenarios, all tasks lie in the responsibility of only one operator who is in charge of every decision on story creation, reporting, and interviews, as well as recording and video capturing. Moreover, in many cases, the journalist is not specialized and properly trained in camera and microphone operation techniques. In order to address the absence of a specialized professional during the recordings, the MoJo-MATE application integrates digital 
signal processing and machine learning algorithmic implementations to provide the user with useful recommendations for efficient audio-visual content creation $[54,55]$.

Several common and repeated mistakes of audiovisual capture were pointed out during the analysis stage. Such mistakes include microphone signal clipping, wrong microphone placement, low signal recording, recording in presence of environmental noise and bad room acoustic conditions, wrong video framing, and video recording with improper exposure (too little or too much light/zebra effect). Errors like these are almost completely avoided when a film specialist and audio engineer are present in a news reporting crew. Treating the faulty audiovisual assets during post-processing is a time-consuming process which typically results in content of an inferior quality compared to properly captured videos and recordings. Several automated algorithmic processes have been proposed and implemented in order to recognize such faults in the terminal side during production and to warn the journalist that some action is needed in order to improve the quality of the captured content during recording. The inspiration for these features came from the field of robot videography [56], where intelligent agents make decisions and operate recording devices. In our case, the intelligent agents provide the user with recommendations about optimal settings, but the user has to make the final decision. The Graphic User Interface (GUI) for audio and video recording modality, as well as the modalities for sharing and manipulating the content and the automatically created semantic metadata are shown in Figure 1, along with the MoJo MATE logo.
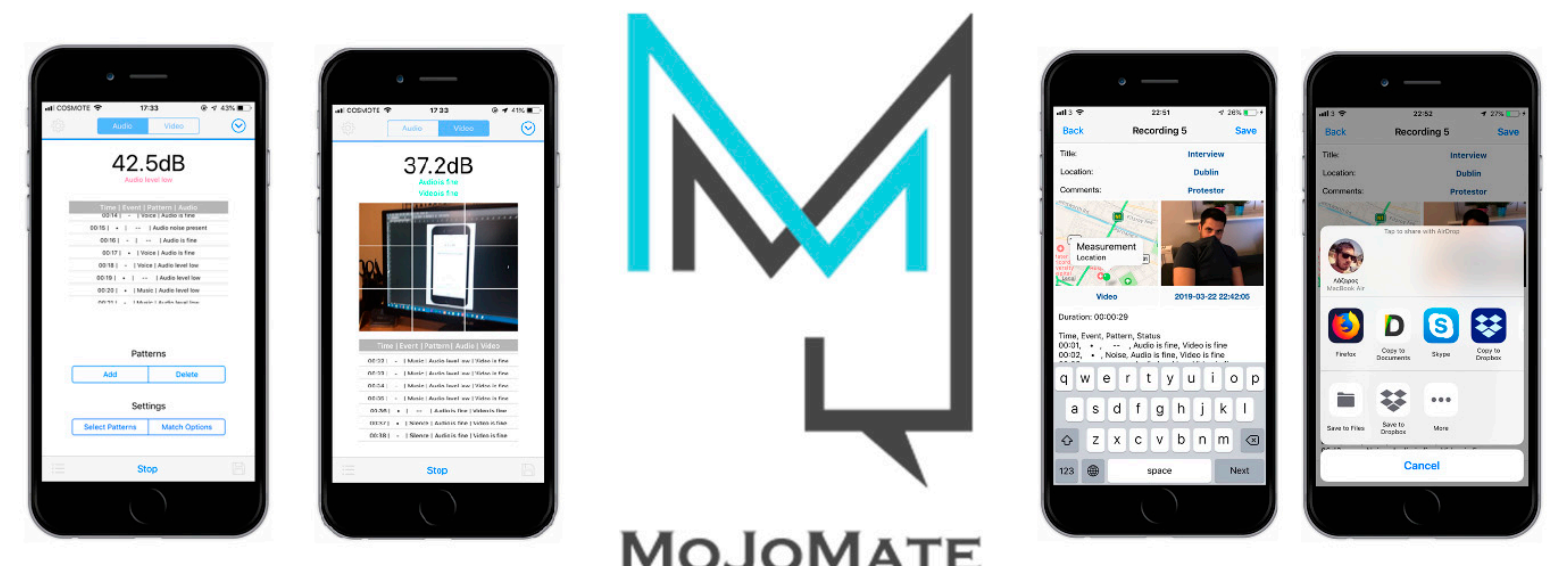

Figure 1. The mobile journalism machine assisted reporting platform (MoJo-MATE) terminal side. The mobile application contains modalities for the intelligent support of audio and video creation, as well as the sharing of the content along with automatically generated semantic annotation.

The content that is created using the dedicated application is uploaded to the cloud along with the supplementary metadata file in order to be accessible by the rest of the collaborators. The server side of the MoJo-MATE platform provides the databases where the stories are stored, along with their respective metadata, users, roles, and user rights. The multimedia stories created in the terminal side of contributors can be accessed on the server side by multimedia experts and editors. Through this process, the stories are processed, mistakes that occurred during creation are corrected, and the stories are rendered ready for publishing after final approval. The functionality of the server side is provided through a dedicated website.

\subsection{In Situ Learning through the Collaborative MoJo-MATE Platform}

The MoJo-MATE is not oriented to serve as a dedicated educational platform. The core motivation behind its development is the support of modern newsrooms in incorporating mojo practices efficiently. By taking advantage of the cloud collaboration of multidisciplinary experts, as well as automated procedures for the intelligent support of content creation, it is feasible to raise the bar of quality expectations in mojo stories. Professionals can be negative towards supplementary 
training [42], which stresses their time schedules and adds additional work hours. The in situ en-skilling of professionals in media literacy while supporting their everyday tasks lies within the goals of MoJo-MATE. This is why it was designed as an out-of-the-box, easy to use solution that requires no previous training by mojo professionals but immediately increases their efficiency. Meanwhile, the user is trained gradually thanks to the two core elements of the proposed framework: Artificial intelligence automation/recommendations and collaborative work.

First of all, the in-app recommendations concerning common recording mistakes, besides aiding the user to improve the quality of the recording, provide her/him with useful insight on proper audio-visual recording techniques without having to turn to theory and handbooks. The more the user identifies common flaws that are pointed out by the application, the less likely it is to repeat them, thus promoting media literacy in terms of the ability to create quality content in the new media [38]. This applies equally to professional journalists and citizens who use the application in order to contribute news-reporting material. Secondly, working in a multidisciplinary environment that is interconnected on the cloud (on the server side) facilitates collaborative learning. The mobile journalists create and edit stories which are then edited by the multimedia experts in a common platform in order to make final corrections and adjustments. The editing history is saved in a log file that is accessible to both user categories. This way, the journalists can take regular feedback from the experts, thus allowing them to identify faults in their originally created audio and video files which needed special treatment during post-processing. This procedure is expected to be very beneficial in the long run, making it possible for journalists to recognize common mistakes that should be avoided. The process of on-the-work learning while using the MoJo-MATE platform is depicted in Figure 2.

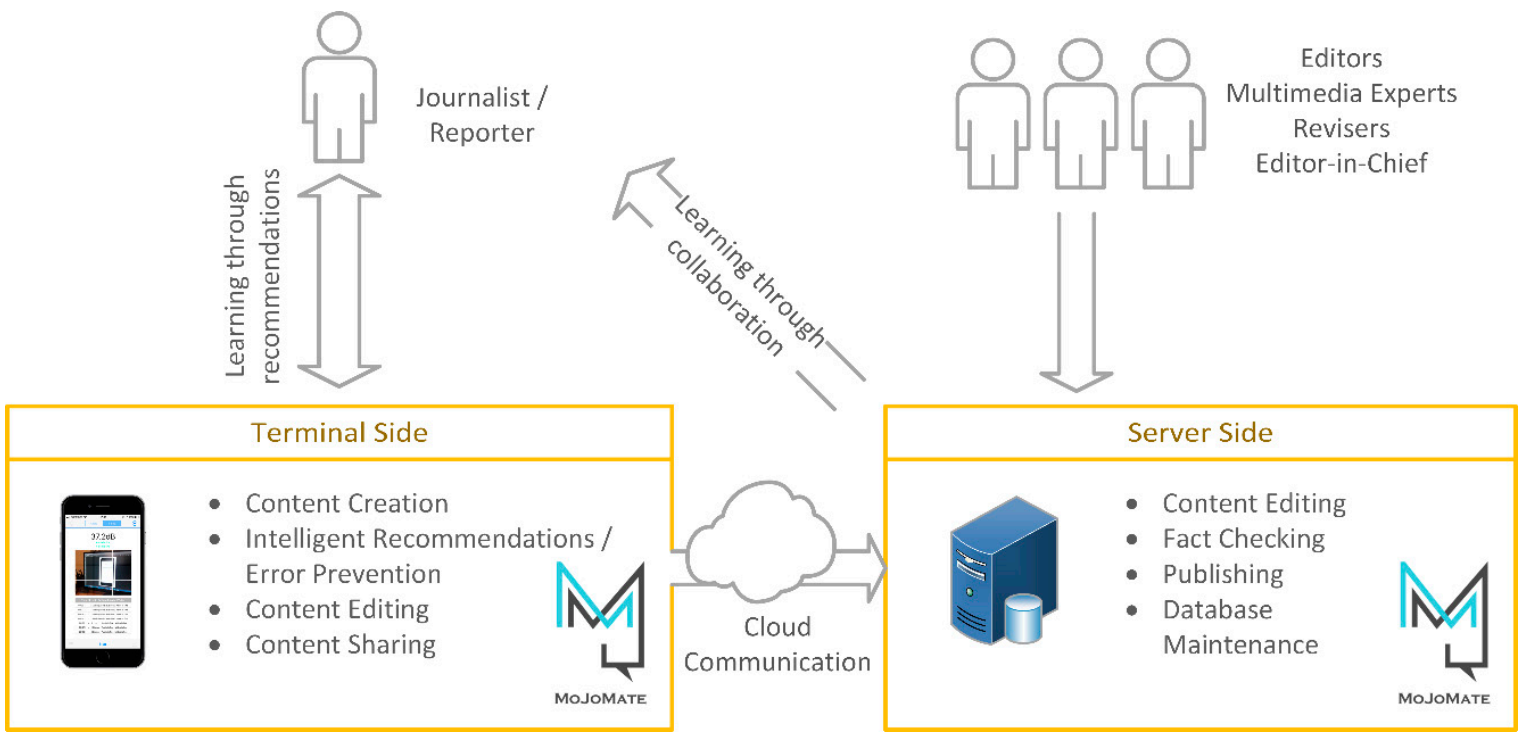

Figure 2. Learning through the common workflow cycle of the MoJo-MATE platform.

For all of the aforementioned reasons, a big part of the iterated evaluation stages is about testing and improving the MoJo-MATE terminal side implemented versions in terms of ease of use and learning by inexperienced users. It is important to ensure that the target users are capable of using the application on their own, without the help of a technological expert. This way, we can be sure that they are immediately able to start benefiting from the procedure in terms of media literacy and digital skills development.

\subsection{Methodology}

As mentioned, we adopted typical software/system development models, utilizing logical user-centered design (LUCID) [52]. The LUCID model proposes iterations between the stages of envision, analyze, design, refine, implement, and support. Specifically, starting with the basic idea, 
a thorough analysis was conducted as a part of a "rapid interactive prototyping" procedure which featured intense user engagement. Evaluation metrics (prior and after the design) were employed to validate the constructed model, providing assessment results in qualitative and quantitative terms. The current research corresponds to the stages of analyzing user needs and requirements, refining the prototype that was proposed in the design stage, and implementing through public testing and evaluation, as described in the LUCID model.

\subsubsection{Participants}

Altogether, 73 participants took this survey. The inclusion criteria for them were the following: a) A willingness to participate in the study, and b) they were considered to be internet users and have an email account so they could receive the online questionnaire. Because this survey was to be used as an initial analysis on the subject, we only chose core collaborative web functionalities to be questioned in students, i.e., without any advance applications that computer supported cooperative work (CSCW) might have.

\subsubsection{Procedure}

The potential participants who fulfilled the eligibility criteria were approached by our research team. The aim of the study was explained, and they were asked whether they were willing to participate in the study. The participants had the opportunity to ask questions about the study. The questionnaire consisted of two parts which corresponded to different research questions. The first part aimed at analyzing the participants' needs, work habits, and their fluency with issues related to mobile journalism. In the second part, the current implemented version of the MoJo MATE platform was evaluated. After a short introduction where a member of our research group presented the main MoJo MATE functionality, we handed iPhone devices to the participants in order to allow them to go through the work cycle on their own, alone, or in collaboration with their colleagues. The questionnaire was administered to the students in the form of an online survey created using the Google Forms free tool. A major advantage of this was that it was easy to import the data at once to dedicated statistical software. After suitable pre-testing and reviews, the questionnaire was composed of 34 close-ended questions. Out of the closed type, 15 were Likert-type, containing 5 ordinal answers mapped to a 1-5 integer scale. In addition to these questions, the participants had the opportunity to answer open-ended questions concerning the advantages and disadvantages of the systems, as well as their own requirements, in order to have qualitative feedback. The open group discussion that followed was another opportunity to collect responses and comments in an unstructured form.

\subsubsection{Data Analysis}

After collecting the data, it was coded and inserted in IBM SPSS Statistics Version 25, which was the software selected for the statistical analysis. In the following section of the paper, descriptive statistics of all items are presented and analyzed, and correlations between variables are researched and further explored as well.

\section{Results}

\subsection{Demographics}

Almost all of the participants (95.9\%) were undergraduate students. In total, $22.2 \%$ of them were males, and $77.8 \%$ were females, as shown in Table 1 . Most of the participants (95.9\%) belonged to the 18-24age group, $1.4 \%$ belonged to the $25-30$ age group, $1.4 \%$ belonged to the $40-50$ age group, and $1.4 \%$ belonged to the $50-60$ age group. Almost half of them, $53.4 \%$, stated that they were not familiar with mobile journalism before, but most of them $(91.8 \%)$ had participated in a mobile survey. 
Table 1. Demographics.

\begin{tabular}{|c|c|}
\hline Aspects & Absolut (relative) Frequency \\
\hline $\begin{array}{l}\text { Gender } \\
\text { - male } \\
\text { - female }\end{array}$ & $\begin{array}{l}22.2 \% \\
77.8 \%\end{array}$ \\
\hline $\begin{array}{ll} & \text { Age } \\
\bullet & 18-24 \\
\text { • } & 25-30 \\
\text { ? } & 30-40 \\
\text { - } & 40-50 \\
\text { - } & 50-60\end{array}$ & $\begin{array}{c}95.9 \% \\
1.4 \% \\
1.4 \% \\
1.4 \%\end{array}$ \\
\hline Total & \\
\hline
\end{tabular}

The journalistic profile of the students was defined with two questions regarding their willingness on the media type ("Which of the following media are you interested in?") and work ("Which of the following media work are you interested in?"). The answers to the first question indicated that $31.5 \%$ of the students are interested in online journalism, $24.7 \%$ of them are interested in both television and radio, and $12.3 \%$ of them are interested in print media. The answers to the second question indicated that most of the students are interested in entertainment media $(24.7 \%)$, political media $(17.8 \%)$, and sports media (13.7\%). A percentage of $11 \%$ are interested in working as a chief editor in a media organization. Finally, the social media profile of the participants ("Which of the following social media do you use?") indicated that 54.8\% use Facebook, 37\% use Instagram, and 20.5\% use Twitter.

\subsection{Technological and Functional Capabilities of Mobile Devices/Applications and Their Role in Journalistic Practices}

Smartphones were proved the most popular devices for professional use/work, as it is highlighted in Table 2, with computers coming second. In order to realize if the participants have the skillsets and know-how to fully exploit contemporary digital technologies in their usual media work, they were asked to describe their devices daily use: (a) Calling and answering calls, (b) sending and receiving short messages (SMS), (c) reading and writing e-mails, (d) browsing the internet for information, (e) using the internet for social interaction (social networks), (f) playing games, (g) monitoring their health, and (h) monitoring and controlling other devices. In Table 2, these findings are presented in percentages. As revealed by the results, the students use a smartphone for their daily activities.

Most of the participants stated that they mostly perform text-only content editing and processing on their own, as compared to audio, video, and online content. To realize if the participants have in-depth knowledge of the content production and management capabilities of smartphones and mobile devices, they were asked if they use additional technological support (mobile apps) for content editing/processing in their working activities. The results show that the participants are eager (probably yes $=31.5 \%$ and definitely yes $=42.5 \%$ ) to make use of technological support for content editing and processing in daily working activities. Furthermore, the participants think that the quality of the mobile created content would be better if they had the consultation of an expert. 
Table 2. Technological and functional capabilities of mobile devices. The top choice for every task is highlighted.

\begin{tabular}{ccccccc}
\hline & Computer & Smartphone & Tablet & Smartwatch & Other & Total \\
\hline Calling and answering calls & 3.9 & 94.7 & 1.3 & 0 & 0 & 100 \\
Sending and receiving short messages (SMS) & 30.4 & 65.2 & 4.5 & 0 & 0 & 100 \\
Reading and writing e-mails & 44.5 & 50.8 & 3.9 & 0.8 & 0 & 100 \\
Browsing the internet for information & 44.1 & 50.7 & 5.1 & 0 & 0 & 100 \\
Using the internet for social interaction & 35.8 & 59.2 & 5 & 0 & 0 & 100 \\
(social networks) & 35.96 & 57.3 & 4.5 & 0 & 2.2 & 100 \\
Playing games & 24.42 & 68.6 & 2.3 & 3.5 & 1.2 & 100 \\
Monitoring your health & 37.65 & 54.1 & 2.4 & 2.4 & 3.5 & 100 \\
\hline
\end{tabular}

\subsection{Problems, Issues, and Challenges of Mobile Journalism}

Most of the participants (86.3\%) stated that they do not face any challenges due to rapid technological changes. The rest of them were asked about the difficulties that they face. The answers to the question focused on their concerns about (a) the complexity of the devices or applications features, (b) adaptation, and (c) content creation and editing.

In an effort to decode the problems that caused difficulties for students while they use mobile devices for audio content creation, four questions regarding the circumstances were asked. The main causes involved: (a) Smartphone or tablet availability, (b) mobile device performance, (c) familiarity with their mobile device, and (d) a lack of satisfaction with the mobile applications. They had to mention the importance of those factors by choosing among them. The findings provide evidence that all but the (a) of the factors were considered either important or very important. More specifically, the factors-(b) and (c) - were chosen by the $35.6 \%$ and $38.4 \%$, respectively, and the factor (d) was chosen by the $23.3 \%$ of the participants.

Most of the participants (76.7\%) stated that they would prefer a unified application for content production, editing, and publishing.

\subsection{Requirements of a Mojo Application}

To explore what the participants think would be more functional in the learning procedure and could operate supplementary to lectures on the recording techniques, students were asked to state their opinion regarding the features of a mojo application: (a) Simplicity in design/easy navigation; (b) personalized experiences/usability; (c) machine learning; (d) audio semantic extraction; (e) the integration of augmented reality; (f) cross-platform coverage (Android, iOS, Windows); (g) performance; (h) security; (i) social media connection; (j) interoperability with modern connectivity standards; (k) a focus on business-driven solutions; and (l) compliance with the General Data Protection Regulation (GDPR) standards. In Figure 3, the findings are presented in percentages.

As shown by the results, the students need a simple and easily-navigated application for their own productions. It seems that it is in their belief that better media production would come from audio/video semantics extraction features. Moreover, it was encouraging that they asked for a cross-platform model with more focused and personalized usability and capabilities of rapid connection and publishing on social media. Machine learning mechanisms have also been proven pivotal in the educational process when the learner/student is at the center. Last but not least, services concerning security were considered important by the students.

\subsection{Evaluation of the MoJo-MATE Terminal Side Prototype}

For practicality and convenience reasons, it is important that the app MoJo-MATE can be used without restricting everyday life. Table 3 and Figure 3 demonstrate the results of the participants' assessment regarding the MoJo-MATE usability (US), efficiency (EF), and the effects on their skills (SK). Using a comprehensible grading system ranging from " 1 " for strongly disagree, to " 5 " for strongly agree, it could be illustrated that most of the participants evaluated MoJo-MATE to be very good and good. 
Usability (US): Essentially, the MoJo-MATE app is very user-friendly. Usability seems to benefit from its well-designed interface and well-integrated functions. The participants felt confident using the MoJo-MATE, and they did not ask for technical support.

Efficiency ( $E F)$ : The results show that potential users can learn to use the application very quickly. The respondents rated efficiency above average in most cases, showing that they believe that they will be supported to implement the best practices for audio capturing/editing through the use of the presented platform. Moreover, it was not indicated that they were in urgent need of acquiring additional skills before they are ready to work with MoJo-MATE.

Effects on their skills (SK): Finally, respondents thought that MoJo-MATE use also poses benefits for individual and teamwork skills. Their work skills and team awareness seem to benefit more according to the rating scale, which indicated positive feedback. The contribution to the improvement of their skills on audio capturing/editing techniques was above the average. It is worth noting that the participants stated that they would be very interested in more educational content for audio capturing/editing techniques provided by the MoJo-MATE application.

Table 3. MoJo-MATE evaluation (1: Strongly disagree, 5: Strongly agree).

\begin{tabular}{|c|c|c|c|}
\hline & Minimum & Maximum & Mean \\
\hline I thought the MoJo-MATE was easy to use. (US 1) & 2.0 & 5.0 & 3.85 \\
\hline I thought that I would need support by technical staff. (US2) & 1.0 & 5.0 & 2.48 \\
\hline I thought that users' manual is necessary. (US 3) & 1.0 & 5.0 & 2.29 \\
\hline I found the various functions in the MoJo-MATE were well integrated. (US 4) & 1.0 & 5.0 & 3.84 \\
\hline I thought that the MoJo-MATE interface is very useful for system training. (US 5) & 2.0 & 5.0 & 3.68 \\
\hline I would imagine that most people would learn to use this very quickly. (EF 6) & 1.0 & 5.0 & 3.73 \\
\hline I felt very confident using the MoJo-MATE. (US 7) & 1.0 & 5.0 & 3.55 \\
\hline I needed to learn a lot of things before I could get going with this. (EF8) & 1.0 & 5.0 & 2.51 \\
\hline I used to make mistakes and I couldn't find the way to solve them. (US9) & 1.0 & 5.0 & 2.37 \\
\hline The basic functions are easy, and the user can remember them. (US10) & 1.0 & 5.0 & 3.7 \\
\hline The MoJo-MATE helps to implement the best practices for audio capturing. (EF11) & 1.0 & 5.0 & 3.7 \\
\hline $\begin{array}{c}\text { Using MoJo-MATE, my skillset on audio content capturing/editing techniques were } \\
\text { improved. (SK12) }\end{array}$ & 1.0 & 5.0 & 3.67 \\
\hline $\begin{array}{l}\text { I would be interested in the MoJo-MATE if more educational content for audio } \\
\text { capturing/editing techniques. (SK13) }\end{array}$ & 1.0 & 5.0 & 3.88 \\
\hline I think that I would like to use the MoJo-MATE frequently. (EF14) & 2.0 & 5.0 & 3.81 \\
\hline I would suggest this to a colleague. (EF15) & 2.0 & 5.0 & 4.1 \\
\hline
\end{tabular}

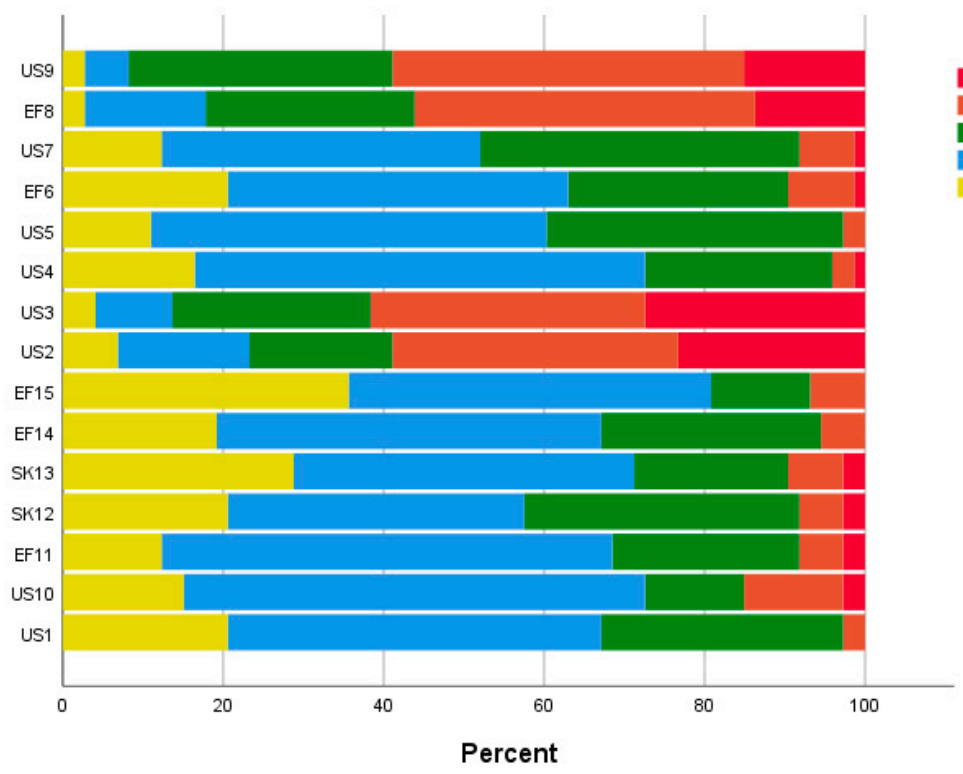

Figure 3. Responses of the participants regarding the MoJo-MATE usability (US), efficiency (EF), and the effects on their skills (SK). 


\subsection{Open-Ended Questions and Group Discussion}

Participants commented about how they evaluated the pros and cons of using the MoJo-MATE application. The basic benefits that were highlighted in the focus group discussion were the clear understanding of use, the simplicity of the interface, the content export quality, and the available recommendations for audio content capturing and editing:

"Simple" [P1, P3, P18].

"Users skills will be improved" [P17], "Better audio data capturing/editing supported by MoJo-MATE notifications/recommendations."

"MoJo-MATE facilitates the data collection using a smartphone for journalistic purposes" [P20].

Several issues were raised about the application's compatibility and the necessity for more simple functions, neither of which will make delays in the journalistic process:

"The application should be developed for the Android platform." [P4, P24, 45].

"The journalists need applications with automated functions that will support them to do their work faster"

Some of the participants' worries in the open-ended questions concerned the nature of the field of mobile journalism. The transfer of responsibilities from audiovisual recording experts to reporters creates doubts among journalists.

Finally, most of their suggestions for the MoJo-MATE improvement included the integration of advanced functions of the audio content capturing/editing, as well as training material for a better understanding of these processes.

\section{Discussion}

The results of the surveys were very informative for both the target audience analysis and the prototype evaluation. The habits, maturity, preferences, and needs of the potential users were investigated, and we had the chance to evaluate the prototype of the terminal side in order to have a useful insight concerning how well its goals are delivered.

Text is the medium preferred by most participants, with audio and video coming second and third. Text has traditionally been the dominant medium in journalism, and the results may indicate that the users are not as familiar with audio-visual content creation. This highlights the need for a framework that supports such tasks.

Smartphones are considered the most popular device for content sharing, and the majority of the participants use smartphones for content editing and creation. An even bigger majority were willing to intensify their use of mobile devices in the future. These outcomes strengthen our hypothesis concerning the maturity of the technological ecosystem for mojo integration in newsrooms. The majority of the participants felt confident about their ability to cope with technological advances in the field. It is, however, notable that, despite their familiarity with mobile devices and their experience in journalism, most of them were not aware of the term mobile journalism. This seems contradictory, keeping in mind that they have incorporated mojo practices in their work. The goals set by the MoJo-MATE platform can help in the direction of providing a more systematic approach and comprehension of mojo through on-the-work training.

The main reasons that the participants stated for being hesitant about the use of mobile devices are a lack of confidence, an absence of an inspiring and helpful application, and a mistrust of the performance capabilities of the users' smartphones. While the latter is being addressed by the industry with the rapid development of affordable devices, the first two reasons are within the core aims of the MoJo-MATE platform. Having access to a dedicated application that integrates all the functionality needed by professional journalists and that supports them in developing their media skills will arm the 
users with strengthened confidence and motive to apply mojo practices in their everyday professional activities. This is clear, since more than $90 \%$ of the participants were positive that the quality of the audiovisual content they create could improve with proper guidance. Moreover, the big majority preferred one unified platform integrating all functionality. This was the initial insight into our research team, since an integrated solution lifts the burden of having to search, try, and evaluate different applications and having to learn and adapt to multiple environments.

During the evaluation part of the MoJo-MATE terminal side (iOS application), the targeting of our research concerned the satisfaction of the criteria of learnability, efficiency, error tolerance, memorability, and user satisfaction. Our goal is to provide journalists with a tool that supports them with mojo tasks without prior training in order to provide them with an on-the-work learning experience. It is, consequently, very important to ensure that users are capable of using the application on their own. The results, as presented in Section 3.5, show that users feel confident about using the app, think that the graphic user interface is an efficient guide, and believe that most users should be able to use them. However, in the following questions, many of the respondents answered that they would want some guidance from a technological expert or written instructions. This has to be taken into consideration in order to create supplementary material to accompany the application or a presentation of the main functionality by an expert. In practice though, all participants were able to operate the application at a satisfactory level at first contact, which leads us to the assumption that even those who seek the safety of a user manual or expert support are actually able to learn everything on their own in a short time.

It seemed to be a common belief among participants that they had to learn things in order to operate the application. However, the majority declared that they memorized the main operations for future reuse of the application. This is not contradictory to the MoJo-MATE scope, since it is desired for users to learn by experience while using the platform. This process is constructive since the interface makes it easy to memorize it.

Most participants more or less favor the process of developing their skills in audiovisual content creation by practice without having to refer to theory handbooks. They believe that using the application, along with the in-app automated recommendations, helps them learn and adopt the best audiovisual recording techniques. It was, however, indicated that, besides learning by experience, they would like the system to offer them additional information. Integrating theory in the form of optional tips that are accessible while using the application can be part of future development plans. Finally, it is highly motivating that most participants declared that they were satisfied with the MoJo-MATE platform, want to use it often, and suggest it to colleagues.

The request of many participants in the open-ended questions for an Android version of the application that can be installed in their phones is an interesting indicator about how journalists consider mobile journalism more linked to their personal devices and habits rather than a dedicated tool for professional use. This confirms the claim that mojo acts as a bridge between professional and personal use of mobile devices.

\section{Summary and Conclusions}

We have presented a framework that facilitates the in situ media literacy development of professional journalists and citizen contributors without supplementary training. The en-skilling process of journalists can become feasible through the use of a cloud collaborative model that incorporates machine-assisted mojo practices in an interconnected newsroom. The MoJo-MATE platform was prototyped and evaluated for this cause. It contains a terminal side that runs on smartphones and integrates intelligent systems to assist quality content creation, and it contains a server side that allows for cloud collaboration and the interconnection of all newsroom contributors. While the main goal of the MoJo-MATE platform is to improve the quality of mojo stories and implement the complete workflow of a newsroom, working within this framework is expected to improve users' new media capabilities. 
For user requirements analysis and the evaluation of the MoJo-MATE prototype, a survey based on online questionnaires was held, with a focus on student and professional journalists. Results indicate that journalists are very familiar with using their smartphones for content creation and sharing. However, the utility for a dedicated application in order to help them improve the quality of their created audiovisual content was highlighted by the majority of the respondents. In the second part of the survey, they evaluated the prototype of the MoJo-MATE iOS application. The journalists were able to use it without prior experience and found out that the Graphic User Interface allows them to easily learn and memorize its functionality. While they did not face any difficulties using the application, most of them stated that they felt like they needed help or written instructions. The majority declared that they were satisfied, they would suggest the application, and they would recommend it to colleagues.

The outcomes of our present research support our initial research hypotheses. Modern journalists are familiar with smart mobile phones and are willing to use them more intensively in the future for content creation. However, most of them feel unconfident about creating quality content, especially audio-visual creation. They favor in situ learning, which is provided by the MoJo-MATE platform through collaboration and in-application intelligent recommendations. The framework and the application that we presented had positive feedback, and the comments, objections, and recommendations we gathered were valuable and very productive. Our research team intends to take them all into account for the development of the next versions of the platform so that it can suit their needs before it is provided to a broader journalistic audience.

Author Contributions: Conceptualization, E.S., L.V., and C.D.; methodology, E.S. and N.V.; software, L.V.; validation, E.A.; investigation, E.A. and C.D.; data curation, E.S. and N.V.; writing-original draft preparation, E.S., N.V., and L.V.; writing-review and editing, E.A. and C.D.; supervision, C.D.; project administration, C.D.

Funding: This research was partially supported by the Operational Program "Human Resources Development, Education and Lifelong Learning" and is co-financed by the European Union (European Social Fund) and Greek national funds.

Conflicts of Interest: The authors declare no conflict of interest.

\section{References}

1. Dimoulas, C.; Veglis, A.; Kalliris, G. Application of mobile cloud based technologies in news reporting: Current trends and future perspectives. In Mobile Networks and Cloud Computing Convergence for Progressive Services and Applications; Rodrigues, J., Lin, L., Lloret, L., Eds.; IGI Global: Hershey, PA, USA, 2014; Chapter 17; pp. 320-343.

2. Katsaounidou, A.; Dimoulas, C.; Veglis, A. Cross-Media Authentication and Verification: Emerging Research and Opportunities; Authored book, contracted for publication in the "Advances in Multimedia and Interactive Technologies (AMIT)" book series; IGI-Global: Hershey, PA, USA, 2018.

3. Dimoulas, C.A.; Symeonidis, A.L. Syncing shared multimedia through audiovisual bimodal segmentation. IEEE MultiMedia 2015, 22, 26-42. [CrossRef]

4. Kalliris, G.; Dimoulas, C. Audiovisual content management issues for the new media environment. In Proceedings of the International Conference on New Media and Information: Convergences and Divergences, Athens, Greece, 3-6 May 2009.

5. Vrysis, L.; Tsipas, N.; Dimoulas, C.; Papanikolaou, G. Crowdsourcing audio semantics by means of hybrid bimodal segmentation with hierarchical classification. J. Audio Eng. Soc. 2016, 64, 1042-1054. [CrossRef]

6. Willacy, H.; Calder, N. Making mathematics learning more engaging for students in health schools through the use of apps. Educ. Sci. 2017, 7, 48. [CrossRef]

7. Elphick, M. The impact of embedded iPad use on student perceptions of their digital capabilities. Educ. Sci. 2018, 8, 102. [CrossRef]

8. Cho, K.; Lee, S.; Joo, M.H.; Becker, B. The effects of using mobile devices on student achievement in language learning: A meta-analysis. Educ. Sci. 2018, 8, 105. [CrossRef]

9. Yurdagül, C.; Öz, S. Attitude towards mobile learning in english language education. Educ. Sci. 2018, 8, 142. [CrossRef] 
10. Uther, M.; Ylinen, S. The role of subjective quality judgements in user preferences for mobile learning apps. Educ. Sci. 2019, 9, 3. [CrossRef]

11. Sidiropoulos, E.A.; Kotsakis, R.G.; Dimoulas, C.A.; Kalliris, G.M.; Veglis, A.A. Audio semantic and intelligent processing concepts in the new media environment: A cloud computing model. In Proceedings of the 7th Greek National Conference “Acoustics 2014", Thessaloniki, Greece, 20-21 October 2014; pp. 395-402.

12. Sidiropoulos, E.A.; Konstantinidis, E.I.; Kotsakis, R.G.; Veglis, A.A. RecApp: A mobile application for ubiquitous and collaborative audio processing. In Proceedings of the Audio Mostly 2015 on Interaction with Sound ACM, Thessaloniki, Greece, 7-9 October 2015; p. 28.

13. Sidiropoulos, E.A.; Konstantinidis, E.I.; Veglis, A.A. Framework of a collaborative audio analysis and visualization tool for data journalists. In Proceedings of the 2016 11th International Workshop on Semantic and Social Media Adaptation and Personalization (SMAP), Thessaloniki, Greece, 20-21 October 2016; pp. 156-160.

14. Vryzas, N.; Sidiropoulos, E.; Vrysis, L.; Avraam, E.; Dimoulas, C.A. A mobile cloud computing collaborative model for the support of on-site content capturing and publishing. J. Media Crit. (JMC) 2018, 4, 349-364.

15. Sidiropoulos, E.A.; Vryzas, N.; Vrysis, L.; Avraam, E.; Dimoulas, C.A. Collecting and delivering multimedia content during crisis. In Proceedings of the EJTA Teacher's Conference 2018: Crisis Reporting, Thessaloniki, Greece, 18-19 October 2018.

16. Vryzas, N.; Sidiropoulos, E.; Vrysis, L.; Avraam, E.; Dimoulas, C.A. Machine-assisted reporting in the era of mobile journalism: The MoJo-MATE platform. In Proceedings of the 5th International Conference on Communication and Management (ICCM2019), Athens, Greece, 15-18 April 2019.

17. Veglis, A. Comparison of course support environments: Commercial versus open source software. Inf. Educ. Int. J. 2005, 4, 281-292.

18. Bull, A. Multimedia Journalism: A practical Guide; Routledge: Abingdon, UK, 2010.

19. Gray, J.; Chambers, L.; Bounegru, L. The Data Journalism Handbook; O'Reilly Media, Inc.: Sebastopol, CA, USA, 2012.

20. Veglis, A. Education of journalists on icts: Issues and opportunities. J. Appl. J. Media Stud. 2013, 2, $265-279$. [CrossRef]

21. Rosenbaum, H.; Swan, B. Problem-based learning in new media education: The case for human-computer interaction. Hum. Comp. Interact. Theory Pract. 2003, 1, 401.

22. Sidiropoulos, E.; Veglis, A. Computer supported collaborative work skills for future journalists. In Proceedings of the 6th International Conference of Education, Research and Innovation, Seville, Spain, 18-20 November 2013.

23. Matsiola, M.; Spiliopoulos, P.; Kotsakis, R.; Nicolaou, C.; Podara, A. Technology-enhanced learning in audiovisual education: The case of radio journalism course design. Educ. Sci. 2019, 9, 62. [CrossRef]

24. Lappa, A.; Veglis, A. Evaluating ICT knowledge of journalism students. In Proceedings of the 3rd Greek Conference on Informatics Education, Korinthos, Greece, 7-9 October 2005. (In Greek).

25. Klimova, B.; Poulova, P. Mobile learning in higher education. Adv. Sci. Lett. 2016, 22, 1111-1114. [CrossRef]

26. Cheung, S.K.S. A case study on the students' attitude and acceptance of mobile learning. In CCIS 2014; Springer: Berlin/Heidelberg, Germany, 2015; pp. 45-54.

27. Mcloughlin, C.; Lee, M. Pedagogy 2.0: Critical challenges and responses to Web 2.0 and social software in tertiary teaching. In Web 2.0-Based E-Learning: Applying Social Informatics for Tertiary Teaching; Lee, M., Mcloughlin, C., Eds.; IGI Global: Hershey, PA, USA, 2010.

28. Traxler, J.E.; Wishart, J.E. Making Mobile Learning Work: Case Studies of Practice; ESCalate, The Higher Education Academy: Bristol, UK, 2011.

29. Ashton, D. The Professional in the Age of the Amateur: Higher Education and Journalism On-the-Work. 2009. Available online: http://theendofjournalism.wdfiles.com/local--files/danielashton/Daniel\%20Ashton.doc (accessed on 2 July 2019).

30. Koponen, T.; Väätäjä, H. Early adopters' experiences of using mobile multimedia phones in news journalism. In Proceedings of the European Conference on Cognitive Ergonomics: Designing beyond the Product-Understanding Activity and User Experience in Ubiquitous Environments, VTT Technical Research Centre of Finland, Otaniemi, Finland, 30 September-2 October 2009.

31. Martyn, P.H. The Mojo in the third millennium: Is multimedia journalism affecting the news we see? J. Pract. 2009, 3, 196-215. [CrossRef] 
32. Guribye, F.; Nyre, L. The changing ecology of tools for live news reporting. J. Pract. 2017, 11, 1216-1230. [CrossRef]

33. Mills, J.; Egglestone, P.; Rashid, O.; Väätäjä, H. MoJo in action: The use of mobiles in conflict, community, and cross-platform journalism. Continuum 2012, 26, 669-683. [CrossRef]

34. Westlund, O. News consumption in an age of mobile media: Patterns, people, place, and participation. Mob. Med. Commun. 2015, 3, 151-159. [CrossRef]

35. Maniou, T.A.; Papadopoulou, L. Broadcast journalism: Television. Int. Encycl. J. Stud. 2019, 1-11. [CrossRef]

36. Maniou, A.T.; Veglis, A. 'Selfie journalism': Current practices in digital media. Stud. Med. Commun. 2016, 4, 111-118.

37. Maniou, T.; Panagiotidis, K.; Veglis, A. The politicization of selfie journalism: An empirical study to parliamentary elections. Int. J. E Polit. (IJEP) 2017, 8, 1-16. [CrossRef]

38. Livingstone, S. Media literacy and the challenge of new information and communication technologies. Commun. Rev. 2004, 7, 3-14. [CrossRef]

39. Quinn, S.; Burum, I. Mojo: The Mobile Journalism Handbook: How to Make Broadcast Videos With an iPhone or iPad; Focal Press: Waltham, MA, USA, 2015.

40. Burum, I. Democratizing Journalism Through Mobile Media: The Mojo Revolution; Routledge: Abington, UK, 2016.

41. Meyrowitz, J. Multiple media literacies. J. Commun. 1998, 48, 96-108. [CrossRef]

42. Kumar, A.; Mohamed Haneef, M.S. Is mojo (En) de-skilling? Unfolding the practices of mobile journalism in an Indian newsroom. J. Pract. 2018, 12, 1292-1310.

43. Blankenship, J.C. Losing their "mojo"? Mobile journalism and the deprofessionalization of television news work. J. Pract. 2016, 10, 1055-1071.

44. Perreault, G.; Stanfield, K. Mobile Journalism as Lifestyle Journalism? Field Theory in the integration of mobile in the newsroom and mobile journalist role conception. J. Pract. 2019, 13, 331-348.

45. Hussein, B. A blended learning approach to teaching project management: A model for active participation and involvement: Insights from Norway. Educ. Sci. 2015, 5, 104-125. [CrossRef]

46. Naz, N.; Sayyed, A.; Dal Sasso, G.; Khanum, S.; De Souza, M. SavingLife: An educational technology for basic and advanced cardiovascular life support. Educ. Sci. 2018, 8, 78. [CrossRef]

47. Dimoulas, C.A. Multimedia Authoring and Management Technologies: Non-Linear Storytelling in the New Digital Media; Association of Greek Academic Libraries: Athens, Greece, 2015; (In Greek). Available online: https://repository.kallipos.gr/handle/11419/4343 (accessed on 5 May 2019).

48. Nielsen, J. Usability Engineering; Academic Press: Cambridge, MA, USA, 1993.

49. Pressman, S.R. Software Engineering: A Practitioner's Approach, 7th ed.; International Edition; McGraw-Hill: New York, NY, USA, 2010.

50. Sommerville, I. Software Engineering, 9th ed.; Addison-Wesley: Boston, MA, USA, 2011.

51. Vaughan, T. Multimedia: Making it Work, 9th ed.; McGraw-Hill Osborne Media: New York, NY, USA, 2014.

52. Kreitzberg, C. The LUCID Framework. An Introduction. Cognetics Corporation; Princeton Junction: West Windsor Township, NJ, USA, 2008.

53. Psomadaki, O.I.; Dimoulas, C.A.; Kalliris, G.M.; Paschalidis, G. Digital storytelling and audience engagement in cultural heritage management: A collaborative model based on the Digital City of Thessaloniki. J. Cult. Herit. 2019, 36, 12-22. [CrossRef]

54. Vrysis, L.; Vryzas, N.; Sidiropoulos, E.; Avraam, E.; Dimoulas, C.A. Automating audio recording best practices on mobile devices. In Proceedings of the Helina Acoustics 2018 Conference, Patras, Greece, 8-9 November 2018.

55. Vrysis, L.; Vryzas, N.; Sidiropoulos, E.; Avraam, E.; Dimoulas, C.A. jReporter: A smart voice-recording mobile application. In Proceedings of the Audio Engineering Society Convention 146, Dublin, Ireland, 20-23 March 2019.

56. Lan, K.; Sekiyama, K. Autonomous robot photographer with KL divergence optimization of image composition and human facial direction. Robot. Auton. Syst. 2019, 111, 132-144. [CrossRef]

(C) 2019 by the authors. Licensee MDPI, Basel, Switzerland. This article is an open access article distributed under the terms and conditions of the Creative Commons Attribution (CC BY) license (http://creativecommons.org/licenses/by/4.0/). 